\title{
PENERAPAN CORPORATE SOCIAL RESPONSIBILITY (CSR) PT. FARINDA BERSAUDARA DI DESA JAMBUK KECAMATAN BONGAN KABUPATEN KUTAI BARAT
}

\section{IMPLEMENTATION OF CORPORATE SOCIAL RESPONSIBILITY (CSR) PT. FARINDA BERSAUDARA IN JAMBUK VILLAGE, BONGAN DISTRICT, WEST KUTAI DISTRICT}

\author{
Aprillia Tiansih Sulistio* \\ Politeknik Pertanian Negeri Samarinda, Kampus Gunung Panjang, Jl. Samratulangi, \\ Samarinda, Indonesia \\ aprilliatiansih25@gmail.com
}

\begin{abstract}
This research is motivated by the implementation of corporate social responsibility (CSR) for companies to society and the benefits of implementing CSR for the community. Corporate social responsibility (CSR) in a nutshell can be defined as corporate social responsibility to its stakeholders. Companies that implement CSR will benefit, namely maintaining and boosting the reputation and brand image of the company, can improve relations with stakeholders, improve relations with the government, increase employee morale and productivity and get the opportunity to get awards. The company cannot release its responsibility for both the environment and the surrounding community. If the company still wants sustainability, it must pay attention to both the community and the environment.

The purpose of this research is to identify the implementation of CSR by PT. Farinda Bersaudara and identification of benefits received by the community from social, economic and environmental aspects by PT. Farinda Bersaudara. The results of this study indicate that the community's assessment of the company regarding the CSR program on average from the total score of the respondents' answers is 83.44, meaning that most respondents stated that the implementation of CSR at PT. Farinda brothers are good. CSR implementation at PT. Farinda Bersaudara only covers 1 aspect, namely social aspects, for example, such as financial assistance for the 17 August event, religious holidays and also the company providing assistance in the form of buses for school children around the company.
\end{abstract}

Keywords: Corporate Social Responsibility (CSR), Village, Jambuk, Implementation.

\section{PENDAHULUAN}

Tanggung jawab sosial
perusahaan atau Corporate Social
Responsibility (CSR) secara singkat
dapat diartikan sebagai tanggung jawab
sosial perusahaan kepada para
kepentingan (stakeholders). Stakeholders
tersebut merupakan pihak-pihak yang
berkepentingan, baik secara langsung
maupun tidak langsung terhadap
eksistensi atau aktifitas perusahaan,
seperti karyawan, konsumen,
masyarakat, maupun pemerintah.
Perusahaan yang menerapkan
CSR akan mendapatkan keuntungan
yaitu mempertahankan dan mendongkrak
reputasi dan brand citra perusahaan,

dapat memperbaiki hubungan dengan stakeholder, memperbaiki hubungan dengan pemerintah, meningkatkan semangat dan produktivitas karyawan serta memperoleh peuang mendapatkan penghargaan (Wibisono, 2007).

Perusahaan tidak dapat melepaskan tanggung jawabnya baik terhadap lingkungan maupun masyarakat yang ada disekitarnya. Jika perusahaan tetap ingin keberlanjutan, maka perusahaan harus memperhatikan baik masyarakat maupun lingkungan. Perusahaan harus menyadari bahwa dirinya adalah bagian yang tidak terpisahkan dari masyarakat yang lebih luas. Jika saatnya terjadi hal buruk yang menimpa dan merugikan masyarakat, 
maka akan berdampak pada perusahaan juga.

Kepedulian perusahaan sebagai bagian dari tanggung jawab sosial perusahaan yang terwujud dalam komitmen perusahaan untuk mempertanggung jawabkan dampakdampak dari kegiatan usaha yang dijalankan dalam aspek ekonomi, sosial, dan lingkungan. Tanggung jawab sosial perusahaan (CSR) dapat diartikan menjadi dua bagian yaitu ke dalam perusahaan itu sendiri, contohnya terhadap karyawan dan di luar lingkungan perusahaan, seperti menyediakan lapangan pekerjaan kepada masyarakat, peningkatan kesejahteraan masyarakat dan pemeliharaan lingkungan untuk generasi yang akan datang.

Rumusan masalah dalam penelitian ini yaitu bagaimana penerapan Corporate Social Responsibility (CSR) pada PT. Farinda Bersaudara dan apa manfaat dari penerapan Corporate Social Responsibility (CSR) bagi masyarakat.

Adapun batasan masalah dalam penelitian ini yaitu membatasi umur responden untuk didata yaitu antara umur 30-65 tahun, dalam $1 \mathrm{kk}$ hanya dibatasi 1 orang responden saja. Batas tahun terakhir pelaksanaan CSR ini pada 3 tahun terakhir yaitu 2017-2019.

Tujuan dalam penelitian ini yaitu mengidentifikasi penerapan Corporate Social Responsibility (CSR) pada PT. Farinda Bersaudara dan mengidentifikasi apa manfaat yang diterima masyarakat dari penerapan CSR tersebut.

Hasil yang diharapkan dari penelitian ini yaitu dapat menjadi bahan evaluasi bagi perusahaan dalam menetapkan CSR agar dapat meningkatkan kesejahteraan bagi masyarakat sekitar.

\section{METODE PENELITIAN}

\section{Tempat dan Waktu}

Penelitian ini dilakukan di PT. Farinda Bersaudara di Desa Jambuk Kecamatan Bongan Kabupaten Kutai Barat. Penelitian dilaksanakan pada 3 Desember 2019 sampai dengan 15 Desember 2019 untuk pengambilan data
Ialu pada bulan Juli sampai bulan September dilaksanakan pengolahan data dan penyajian laporan penelitian.

\section{Alat dan Bahan}

Alat yang digunakan dalam penelitian ini yaitu handphone, laptop, printer, dan alat tulis. Bahan yang diunakan dalam penelitian ini yaitu lembar kuesioner sebagai pengantar kepada responden dan objek penelitian ini yaitu kepada pemilik perusahaan/ manajer/ asisten manajer dan masyarakat sekitar perusahaan sebanyak 33 responden, dari 120 orang dengan tingkat kesalahan sebanyak $15 \%$.

\section{Teknik pengambilan data}

Simple Random Sampling adalah teknik pengambilan sampel dari anggota populasi yang dilakukan secara acak tanpa memperhatikan strata yang ada dalam populasi itu, teknik ini digunakan jika sampel lebih dari 100 orang (Sugiyono, 2001).

Rumus menurut Sofyan (2017) perhitungan untuk mengukur hasil wawancara dari wawancara antara pemilik perusahaan dan masyarakat sekitar dengan menggunakan rumus sebagai berikut :

1. Rumus Slovin

$$
n=\frac{N}{N d^{2}+1}
$$

Keterangan:

$$
\begin{aligned}
& \mathrm{n}= \text { Ukuran sampel } \\
& \mathrm{N}=\text { Ukuran populasi } \\
& \mathrm{d}=\text { Persen kelonggaran } \text { ketidaktelitian karena kesalahan } \\
& \text { pengambilan sampel yang masih } \\
& \text { dapat ditolerir atau diinginkan, } \\
& \text { diambil sebanyak } 15 \% .
\end{aligned}
$$

Teknik penentuan ini menggunakan Skala likert. Perhitungan pada wawancara menggunakan rumus Slovin untuk menghitung responden mengenai penerapan dan manfaat CSR

Data yang diambil penelitian ini terdiri dari data primer dan sekunder yaitu :

1. Data primer, yaitu data yang diperoleh dari responden dengan mewawancarai langsung kepada masyarakat dan pemilik perusahaan 
dengan pemicu dari pertanyaan yang dibuat penulis.

2. Data sekunder, yaitu data yang diperoleh melalui dokumen-dokumen dan literatur yang ada di perusahaan.

\section{Prosedur kerja}

1. Persiapan, yang akan dilakukan yaitu pembuatan daftar pertanyaan untuk mewawancarai HRD perusahaan dan kuesioner untuk masyarakat sebagai bahan pengumpulan data.

2. Pelaksanaan, mewawancarai HRD perusahaan untuk menanyakan pertanyaan dari daftar wawancara yang dibuat peneliti untuk mengetahui data dari perusahaan kelapa sawit lalu mewawancarai masyarakat sekitar.

3. Pengumpulan data, setelah mewawancarai HRD perusahaan dan masyarakat data tersebut dikumpulkan oleh peneliti dan dievaluasi.

4. Pengolahan data, data yang sudah diperoleh dilapangan kemudian diolah dengan menggunakan software Microsoft Office. Pengolahan data ini menggunakan Skala Likert dengan penentuan skor. Skala Likert dirancang untuk mengukur sikap, persepsi, pendapat seseorang atau kelompok orang tentang fenomena sosial. Jawaban setiap item instrumen memiliki gradasi sangat positif sampai sangat negatif (Juliandi, 2013).

Skala Likert ini digunakan untuk kuesioner penerapan CSR dari perusahaan kepada masyarakat dibuat dengan skala 1-4 kategori jawaban skor yaitu banyaknya skor antara 1 sampai 4 .

Tabel 1. Pedoman Skor Skala Likert

\begin{tabular}{clc}
\hline No. & \multicolumn{1}{c}{ Kategori } & Skor \\
\hline 1 & Sangat baik & 4 \\
2 & Baik & 3 \\
3 & Tidak baik & 2 \\
4 & Sangat tidak baik & 1 \\
\hline
\end{tabular}

Rumus Skala Likert sebagai berikut :

$$
\mathrm{Ts}=\mathrm{T} \times \mathrm{Pn}
$$

Keterangan:

Ts $=$ Total Skor

$\mathrm{T}=$ Total jumlah responden yang memilih

$\mathrm{Pn}=$ Pilihan angka skor likert

Tabel 2. Skala Interval Penerapan CSR

\begin{tabular}{ll}
\multicolumn{1}{c}{ Interval } & \multicolumn{1}{c}{ Karakteristik } \\
\hline $33-57,75$ & Sangat Tidak Baik \\
$57,76-82,51$ & Tidak Baik \\
$82,52-107,27$ & Baik \\
$107,28-132,03$ & Sangat Baik \\
\hline
\end{tabular}

\section{HASIL DAN PEMBAHASAN}

\section{Hasil}

Tabel 7. Hasil Skor Jawaban Responden

\begin{tabular}{|c|c|c|c|c|c|c|}
\hline \multirow{2}{*}{ NO } & \multirow{2}{*}{ Pernyataan } & \multicolumn{4}{|c|}{ Frekuensi } & \multirow{2}{*}{ Total Skor } \\
\hline & & SB & $B$ & TB & STB & \\
\hline 1 & $\begin{array}{l}\text { Masyarakat mengetahui tentang tanggung } \\
\text { jawab sosial perusahaan atau yang biasa } \\
\text { disebut Corporate Social Responsibility } \\
\text { (CSR) }\end{array}$ & 4 & 25 & 4 & 0 & 99 \\
\hline 2 & $\begin{array}{l}\text { Masyarakat mengetahui tentang kegiatan } \\
\text { CSR PT. Farinda Bersaudara }\end{array}$ & 0 & 19 & 14 & 0 & 85 \\
\hline 3 & $\begin{array}{l}\text { Masyarakat mengetahui tujuan PT. Farinda } \\
\text { Bersaudara melakukan program CSR }\end{array}$ & 0 & 22 & 8 & 3 & 85 \\
\hline 4 & $\begin{array}{l}\text { Masyarakat mengetahui kegiatan-kegiatan } \\
\text { yang dibuat oleh PT. Farinda Bersaudara } \\
\text { pada program CSR untuk masyarakat }\end{array}$ & 0 & 5 & 25 & 3 & 68 \\
\hline 5 & $\begin{array}{l}\text { Masyarakat menerima kegiatan CSR yang } \\
\text { dibuat PT. Farinda Bersaudara dengan baik }\end{array}$ & 0 & 16 & 17 & 0 & 82 \\
\hline 6 & Menurut masyarakat terhadap kegiatan & 0 & 25 & 8 & 0 & 91 \\
\hline
\end{tabular}




\begin{tabular}{|c|c|c|c|c|c|c|}
\hline \multirow{2}{*}{ NO } & \multirow{2}{*}{ Pernyataan } & \multicolumn{4}{|c|}{ Frekuensi } & \multirow{2}{*}{ Total Skor } \\
\hline & & SB & $B$ & TB & STB & \\
\hline & $\begin{array}{lll}\text { CSR yang dilakukan PT. } & \text { Farinda } \\
\text { Bersaudara sudah sangat baik } & \end{array}$ & & & & & \\
\hline 7 & Menurut masyarakat pola kegiatan CSR & & & & & \\
\hline & $\begin{array}{l}\text { PT. Farinda Bersaudara sudah sesuai bila } \\
\text { dihubungkan dengan } \\
\text { masyarakat }\end{array}$ & 0 & 16 & 17 & 0 & 82 \\
\hline 8 & Menurut masyarakat bahwa PT. Farinda & & & & & \\
\hline & $\begin{array}{l}\text { Bersaudara melakukan kegiatan CSR atas } \\
\text { dasar tanggung jawab }\end{array}$ & 0 & 13 & 19 & 1 & 78 \\
\hline 9 & $\begin{array}{l}\text { Menurut masyarakat kegiatan CSR yang } \\
\text { dilakukan sudah baik untuk menaikkan citra } \\
\text { perusahaan }\end{array}$ & 0 & 21 & 12 & 0 & 87 \\
\hline 10 & $\begin{array}{l}\text { Masyarakat mendukung kegiatan CSR } \\
\text { yang dibuat PT. Farinda Bersaudara }\end{array}$ & 0 & 26 & 6 & 1 & 91 \\
\hline 11 & $\begin{array}{l}\text { Masyarakat mengikuti dan memperhatikan } \\
\text { perkembangan kegiatan CSR yang } \\
\text { dilakukan PT. Farinda Bersaudara }\end{array}$ & 0 & 16 & 17 & 0 & 82 \\
\hline 12 & $\begin{array}{l}\text { Menurut masyarakat PT. Farinda } \\
\text { Bersaudara sudah } \quad \text { mampu } \\
\text { mengembangkan citra perusahaan atas } \\
\text { kegiatan CSR yang sudah terlaksana untuk } \\
\text { masyarakat }\end{array}$ & 0 & 15 & 18 & 0 & 81 \\
\hline 13 & $\begin{array}{l}\text { Dengan adanya tanggung jawab sosial } \\
\text { untuk masyarakat perusahaan menyisihkan } \\
\text { sejumlah laba untuk masyarakat }\end{array}$ & 0 & 13 & 20 & 0 & 79 \\
\hline 14 & $\begin{array}{l}\text { Dengan adanya anggaran yang disisihkan } \\
\text { untuk program CSR perusahaan } \\
\text { memberikan tanggung jawab kesejahteraan } \\
\text { dan lingkungan masyarakat dengan baik }\end{array}$ & 0 & 14 & 19 & 0 & 80 \\
\hline 15 & $\begin{array}{l}\text { Masyarakat menerima program-program } \\
\text { berdampak positif untuk pelestarian } \\
\text { lingkungan disekitar }\end{array}$ & 0 & 22 & 11 & 0 & 88 \\
\hline 16 & $\begin{array}{l}\text { Dengan adanya program CSR pelayanan } \\
\text { dan pemberdayaan masyarakat dari } \\
\text { perusahaan sudah terjamin }\end{array}$ & 0 & 8 & 17 & 8 & 66 \\
\hline 17 & $\begin{array}{l}\text { Masyarakat menerima perlindungan hak- } \\
\text { hak masyarakat atas kegiatan yang } \\
\text { dilakukan }\end{array}$ & 0 & 32 & 0 & 1 & 97 \\
\hline 18 & $\begin{array}{l}\text { Masyarakat mengetahui perusahaan } \\
\text { memiliki program-program untuk lingkungan } \\
\text { yang berdampak baik bagi masyarakat }\end{array}$ & 0 & 24 & 9 & 0 & 90 \\
\hline 19 & $\begin{array}{l}\text { Dengan adanya program CSR ini bahwa } \\
\text { sudah terencana dengan baik dan ada } \\
\text { proses monitoring serta evaluasi }\end{array}$ & 0 & 17 & 16 & 0 & 83 \\
\hline 20 & $\begin{array}{l}\text { Keterlibatan masyarakat atas program yang } \\
\text { diberikan perusahaan sudah sangat baik }\end{array}$ & 0 & 28 & 5 & 0 & 94 \\
\hline 21 & $\begin{array}{l}\text { Masyarakat menerima juga bantuan atas } \\
\text { dampak pembangunan dari perusahaan } \\
\text { serta menerima fasilitas dan infrastruktur } \\
\text { dengan baik }\end{array}$ & 0 & 13 & 17 & 3 & 76 \\
\hline 22 & $\begin{array}{l}\text { Masyarakat menerima penyediaan energi } \\
\text { listrik dan air dari perusahaan }\end{array}$ & 0 & 30 & 3 & 0 & 96 \\
\hline
\end{tabular}




\begin{tabular}{|c|c|c|c|c|c|c|}
\hline \multirow{2}{*}{$\mathrm{NO}$} & \multirow{2}{*}{ Pernyataan } & \multicolumn{4}{|c|}{ Frekuensi } & \multirow{2}{*}{ Total Skor } \\
\hline & & SB & $B$ & TB & STB & \\
\hline 23 & $\begin{array}{l}\text { Dengan adanya aktifitas yang dilakukan } \\
\text { perusahaan maka perusahaan sudah } \\
\text { mengelola dampak pengambilan air untuk } \\
\text { masyarakat dengan mendaur kembali } \\
\text { dengan baik }\end{array}$ & 0 & 12 & 17 & 4 & 74 \\
\hline 24 & $\begin{array}{l}\text { Dengan adanya kegiatan CSR untuk } \\
\text { masyarakat bahwa perusahaan sudah } \\
\text { mengidentifikasi dampak operasi terhadap } \\
\text { lingkungan dan keanekaragaman hayati } \\
\text { disekitar masyarakat }\end{array}$ & 0 & 22 & 11 & 0 & 88 \\
\hline 25 & $\begin{array}{l}\text { Menurut masyarakat perusahaan sudah } \\
\text { menyisihkan dan untuk pelanggaran yang } \\
\text { dapat merugikan masyarakat sekitar }\end{array}$ & 0 & 7 & 17 & 9 & 64 \\
\hline & Total & & & & & 2086 \\
\hline & Rata-rata & & & & & 83,44 \\
\hline
\end{tabular}

Berdasarkan Tabel 7, didapatkan hasil rata-rata skor 83,44. Hal ini menunjukkan bahwa persepsi masyarakat terhadap penerapan CSR adalah baik.

\section{Pembahasan}

Berdasarkan hasil penelitian pada Tabel 6 yaitu jawaban dari perusahaan bahwa untuk tanggung jawab sosial perusahaan PT. Farinda Bersaudara melaksanakan 2 aspek yaitu aspek sosial dan aspek lingkungan. Contoh aspek sosial yaitu seperti melakukan pelayanan sosial dan pemberdayaan masyarakat, bantuan dana untuk masyarakat saat ada acara hari besar, pemberian dana untuk kesehatan yang dilakukan di puskesmas terdekat, lalu ada pelatihan kesehatan dan keselamatan kerja (K3) juga dulu untuk masyarakat. Lalu, contoh untuk aspek lingkungan yaitu seperti adanya pengambilan sampah setiap seminggu sekali dan mendaur ulang sampah dari pabrik, mengadakan program kesehatan dan keselamatan kerja serta kegiatan lainnya.

Hasil penelitian pada tabel 7 dapat dilihat bahwa total jumlah jawaban masyarakat sebanyak 2086 dibagi dengan 25 pernyataan maka hasilnya 83,44 sehingga penilaian masyarakat berada pada interval dengan kategori "Baik" untuk perusahaan dalam menjalankan CSR. Dapat dikatakan baik karena hanya ada 1 aspek yang dilaksanakan yaitu aspek sosial contohnya seperti bantuan dana untuk acara 17 Agustus, hari besar keagamaan dan juga perusahaan memberi bantuan berupa bus untuk anak sekolah disekitar perusahaan tersebut.

Menurut Elkington dalam Wibisono (2007) mengemukakan bahwa perusahaan ingin berkelanjutan, harus memperhatikan 3P yaitu ekonomi (profit), sosial (people), dan lingkungan (planet). Tetapi dari hasil yang didapat dilapangan hanya 2 prinsip yang terlaksana yaitu sosial (people) dan ekonomi (profit).

\section{KESIMPULAN DAN SARAN}

\section{Kesimpulan}

Berdasarkan hasil dan pembahasan yang telah diuraikan pada bab-bab sebelumnya maka dapat disimpulkan sebagai berikut:

1. Penerapan keselamatan dan kesehatan kerja yang ada di PT. Farinda Bersaudara Palm Oil Mill berpengaruh terhadap kinerja karyawan dengan nilai interpretasi kuat dengan persentase sebesar $66,6 \%$, mengingat bahwa keselamatan dan kesehatan kerja sangat penting bagi pekerjaan.

2. Penggunaan alat pelindung diri pada karyawan di PT. Farinda Bersaudara Palm Oil Mill masih banyak karyawan yang tidak menggunakan alat pelindung diri seperti sarung tangan 
dan earplug dengan alasan pemakaian alat pelindung diri tersebut membuat karyawan tidak nyaman saat bekerja.

\section{Saran}

Dengan melihat kondisi K3 yang ada di PT. Farinda Bersaudara Palm Oil Mill, maka dikemukakan beberapa saran yang diharapkan dapat menjadi bahan pertimbangan untuk langkah-langkah selanjutnya, diantaranya sebagai berikut:

1. Diharapkan pihak perusahaan ini lebih sering memberikan penyuluhan tentang pentingnya penggunaan alat pelindung kepada karyawan agar karyawan lebih mengetahui apa manfaat alat pelindung diri yang ada di perusahaan.

2. Penyediaan fasilitas sarana dan prasarana alat pelindung diri yang layak pada karyawan sehingga karyawan bisa lebih semangat lagi untuk bekerja bila diberikan alat pelindung diri yang memadai.

3. Diharapkan kepada mandor dan atasan lainya lebih tegas dalam memberi istruksi dan lebih sering melakukan monitoring ke setiap stastiun yang ada di pabrik agar karyawan lebih mematuhi peraturan penggunaan alat pelindung diri yang ada di perusahaan.

\section{DAFTAR PUSTAKA}

Arikunto, S. Prosedur Penelitian Suatu Pendekatan Praktik. PT Rineka Cipta. Jakarta. Hal : 131.
Baron, D.P. 2006. Business and its environment. Edisi lima. Pearson

Education Inc. New Jerse: Upper Saddle River.

Budimanta, A. 2008. Corporate Social Responsibility alternatif bagi Pembangunan Indonesia. Cetakan kedua. Indonesia Center For Sustainable Development (ICSD). Jakarta.

Elkington, J. 1997. Cannibals with Forks: The Tripple Bottom Line in $21_{\mathrm{st}}$ Century Business. United Kingdom: Capstone Publishing Limited.

Friedman, A. L. 2006. Stakeholders: Theory and Practice, Jakarta Economic Business. OUP Oxford.

Juliandi, A. 2013. Metode Penelitian Kuantitatif Untuk IImu Bisnis. M2000. Medan.

Kartini. 2009. Corporate Social Responsibility Transformasi Konsep Sustainability Management dan Implementasi di Indonesia.

Sofyan, S. 2017. Statistik Parametrik untuk Penelitian Kuantitatif. Jakarta: PT Indeks Kelompok Gramedia.

Sugiyono. 2001. Statistik untuk Penelitian. Penerbit Alfabeta. Bandung.

Untung, H. B. 2008. Corporate Social Responsibility. Jakarta: Sinar Grafika.Wibisono. 2007. Membedakan Konsep dan Aplikasi Corporate Social Responsibility. Gresik: Fascho Publishing. 